\title{
Case 3: The European Heritage Label
}

\section{The Construction of Europe in the European Heritage Label at the Macro and Meso Levels}

The EU's most recent flagship heritage action, the European Heritage Label (EHL), contributes to the politics of belonging in EU cultural policy by seeking to form 'a community of Europeans' with an emphasis on common values and a shared past in Europe. As the E HL was developed with the aim to strengthen "European citizens' belonging to the Union", heritage sites have been awarded the Label on grounds of their "European significance" and contribution to Europe's history and development (see EC 2010, 2; EC 2011, 6; EP\&C 2011, 3; Lähdesmäki 2014; Čeginskas 2018). The discourse of the EHL action emphasizes the European dimension of heritage, and instead of approaching heritage in terms of conservation, protection, and aesthetic or architectural quality, it treats it as a political instrument that serves identity-building purposes and expectations of economic benefit and sustainable development in the EU (Lähdesmäki et al. 202O). In this respect, the EHL approach corresponds to the recent EU cultural policy of approaching 'Europe' as a brand, promoting a sense of shared unity, commonality, and the benefits of EU membership in terms of 'products' to be mediated to the wider European public.

As one aim of the EHL action is to highlight Europe's cultural diversity, each labelled site has a different thematic context, and visitors interpret the history, heritage value, and meanings of the sites, including their European dimension, in different ways. The heritage sites vary in size, status, and structures depending on their functions as museums, exhibitions, archives, or historical sites, as well as their modes of cultural and educational engagement, practices, and activities. Therefore, the EHL sites manifest a broad temporal, geographical, and cultural variety that mediate events and process from different times, ranging from Roman archaeological remains and reconstructions at Carnuntum Archaeological Park, Austria, to an exhibition of EU integration and institutions in the European District of Strasbourg, France (see Annex 2 for an overview of the EHL sites). At first, it may therefore seem difficult to define any common denominator of 'European' heritage and Europe's past. However, our research shows that by recognizing only heritage sites (e.g. cultural monuments, cultural landscapes, memorials) and intangible heritage associated with a place that symbolizes European integration, common European 
values, and the history and culture of the EU, the EHL constructs a selective discourse of Europe and EU integration as an inevitable and positive trajectory, while retaining awareness of national and regional cultural differences. Furthermore, the EHL's transnational interpretation of cultural heritage challenges dominant national discourses of heritage and promotes a discourse on a common and shared cultural legacy to Europe's citizenry, in which World War II proves to be a turning point for the development of a European civic and political community (e.g. Lähdesmäki 2019). Thus, the purpose of the EHL is to safeguard and develop the process of European integration and to strengthen a unifying European narrative of belonging through the explicit claim to "improve the knowledge and dissemination of the culture and history of European peoples" (EP\&C 2011), built upon the concept of a "shared", but not a homogenized, "European cultural heritage" (see also Niklasson 2017).

Embedded in the EU's multilevel governance, the EHL is based on an interaction between what we call the macro and meso levels of European discourse. The macro level is formed by the EU institutions and the civil servants of the European Commission who shape the EU's discourse on the EHL, and thereby on Europe, with their textual and visual materials, such as policy documents and websites. The main creators of the meso-level EHL discourse are professionals working day-to-day at the awarded EHL sites who formulate, interpret, and put into practice the 'European significance'. As our research shows, they

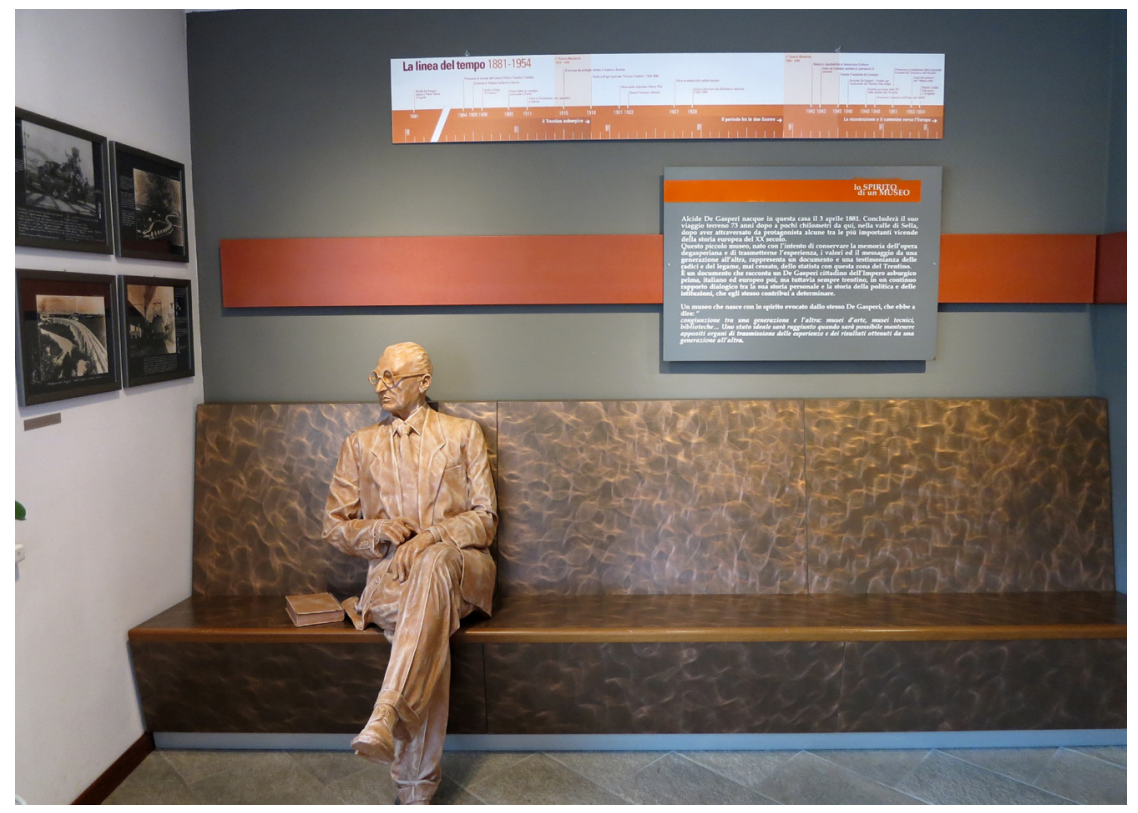

FIGURE 6.1 Alcide de Gasperi House Museum in Italy, an EHL site.

PHOTO: EUROHERIT 


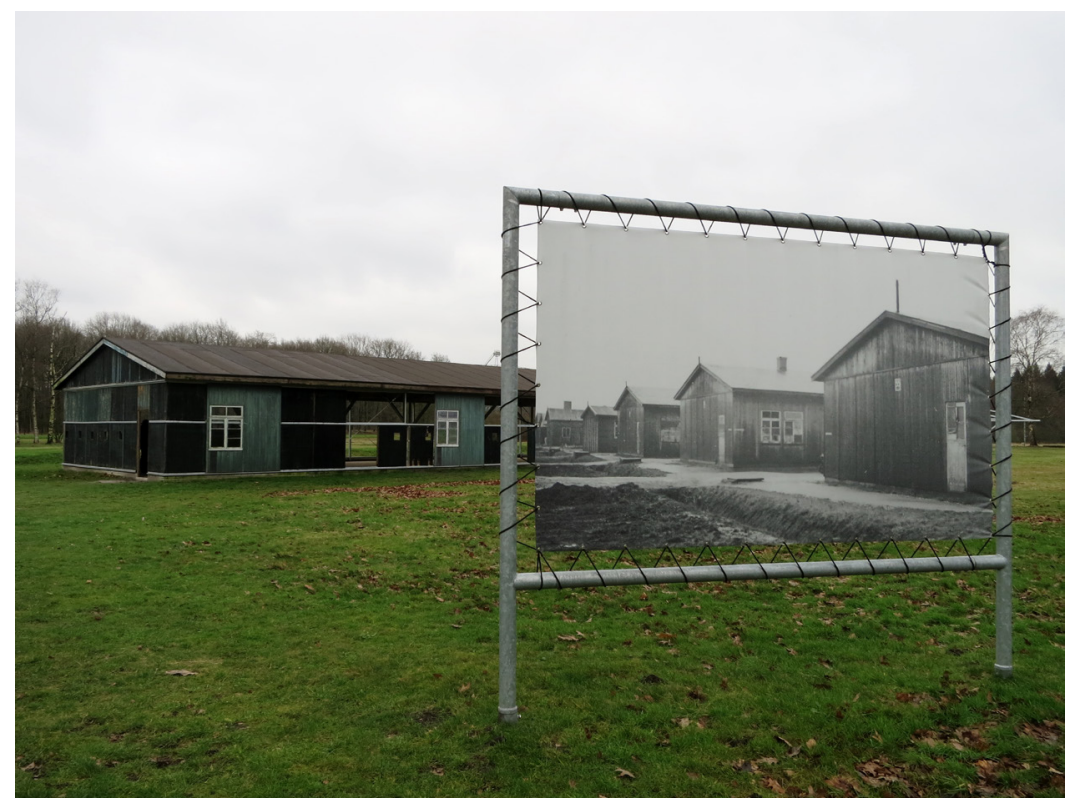

FIGURE 6.2 Camp Westerbork in the Netherlands, an EHL site. PHOTO: EUROHERIT

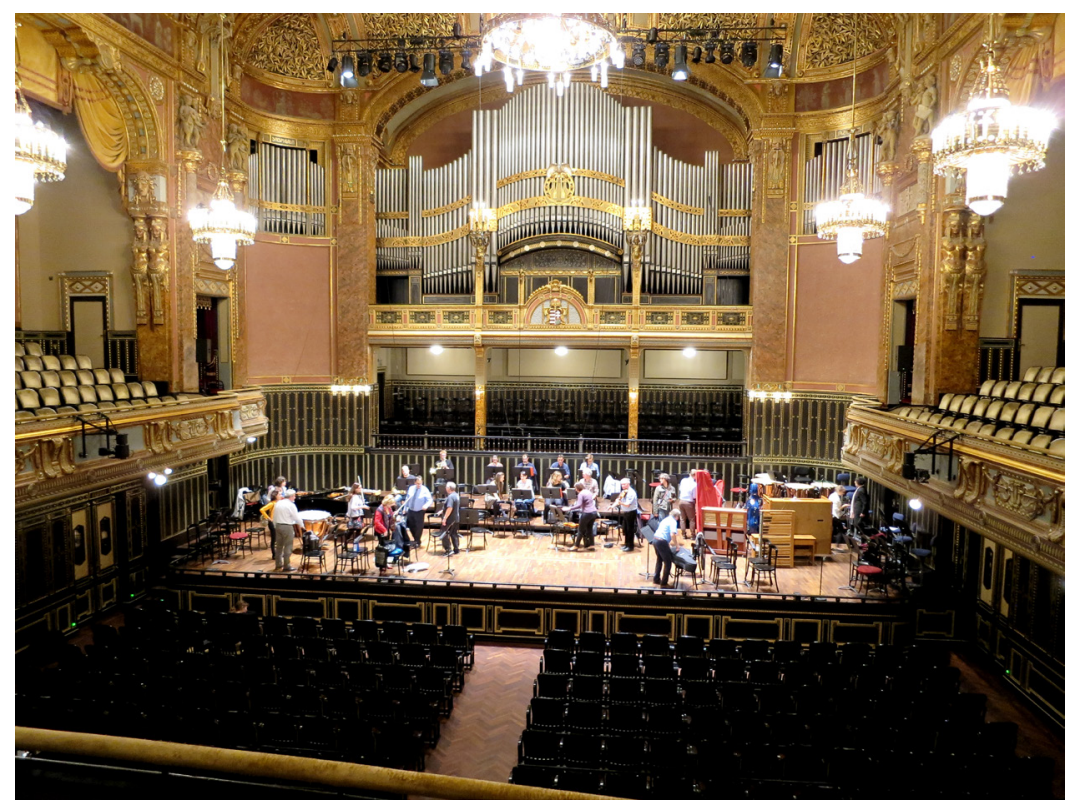

FIGURE 6.3 Franz Liszt Memorial Museum, part of the Franz Liszt Academy of Music in Hungary, an EHL site. PHOTO: EUROHERIT 


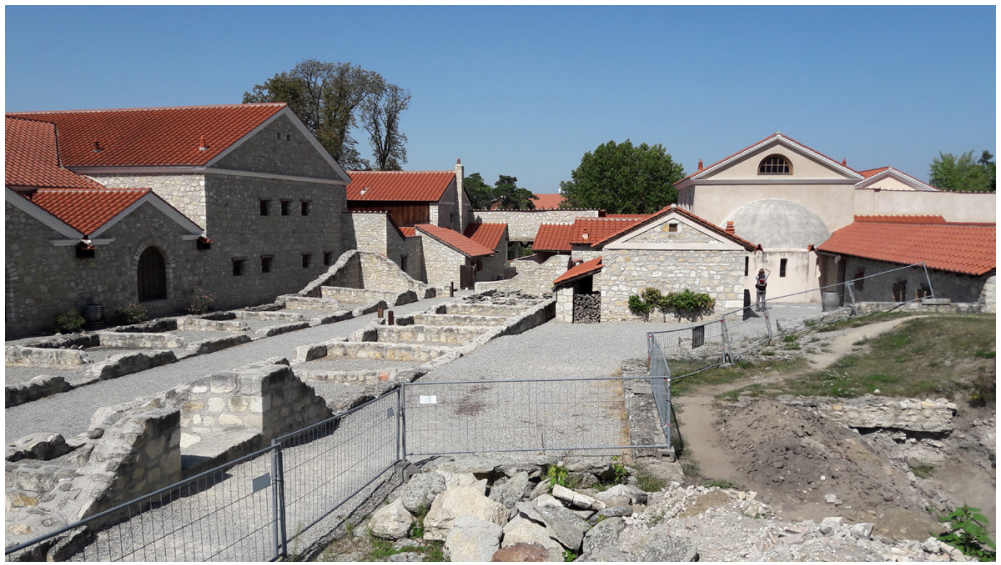

FIgURE 6.4 The Carnuntum Archaeological Park in Austria, an EHL site. PHOTO: EUROHERIT

both follow the macro-level voice and contribute to it by creating contents for the EU discourse (Lähdesmäki et al. 2020). The designation process of the EHL sites exemplifies the interaction between the levels. Sites are pre-selected at the national level, designated at the EU level by an international expert panel, and finally awarded the Label by the European Commission (see Chapter 1).

Our analysis of the EHL data shows that the European Commission and the awarded heritage sites both try to promote 'European' values in terms of social and moral mindsets rooted in political ideals that connect cultural heritage with the promotion of unity, a sense of belonging, and democratic participation (see Lähdesmäki et al. 2020). In the process of constructing European narratives, the EHL discourse mixes local, national, and European scales (Lähdesmäki 2016; Kaasik-Krogerus 2019, 159). As the EH L action involves actors from $18 \mathrm{EU}$ member states and diverse physical and cultural settings (e.g. urban and rural), we argue that the EHL discourse develops from and reveals different perceptions of how 'Europe' and 'the European' are imagined at various levels.

The EHL has a clear educative objective and according to its criteria, designated EHL sites should design pedagogical activities aimed specifically at young European citizens to support the process of European cultural and political integration. According to the EU documents, the designated sites are supposed to promote their European dimension and to 'bring to life' the European narrative (EC 2010, 2; EP\&C 2011, 3; EC 2017). The heritage sites seek to follow these criteria by concretizing the European narrative from their specific perspective, in line with the thematic narrative of the heritage site. However, the views on the 'European' at the meso level do not always meet the views held by the actors at the macro level. This may lead either to candidate sites 
being rejected in the EHL selection process or to a request to strengthen the European dimension at awarded sites. For instance, the EHL monitoring report specifically asked the Great Guild Hall in Estonia to better place its narrative perceived as mainly telling Estonian national history - in a wider European context by emphasizing the story of the Hanseatic League on its website and in its printed materials (EC 2016, 15).

In this chapter, we approach the $\mathrm{EHL}$ action as a means of pursuing politics of belonging. The explicit aim of positively influencing public perception of the EU and strengthening a sense of belonging to it and Europe, in particular among young European citizens, is at the core of the action (EP\&C 2011). As part of this practice, an idea of a common European cultural heritage is formed and used to construct a particular European narrative (Borgmann-Prebil and Ross 2010; Lähdesmäki, Kaasik-Krogerus, and Mäkinen 2019; Čeginskas and Kaasik-Krogerus 2020). In this narrative Europe is constructed as a distinctive political, cultural, and economic entity that enables people to identify as Europeans and feel a sense of belonging to Europe (Sassatelli 2002, 436; Kohli 2000, 118). As regards politics of belonging, communities, in this case first and foremost 'Europe' and the EU, are continuously (re)imagined. 'European significance' as the key criteria of the EHL offers a good example of this process of (re)-imagining.

The promotional videos that introduce the EHL sites and their 'European significance' to the wider public exemplify how the entanglement of the macro and meso levels is enacted in practice in the EHL action. The videos are available on the website of the European Commission, which functions as its public forum to communicate cultural meanings related to Europe. Sixteen of these videos are fully or partly in English, the rest are in various national languages with English subtitles (see also Lähdesmäki, 2017). The videos focus on the respective site's 'European significance', whereas in them, practitioners at the sites commonly evoke an 'imagination' of three, partly overlapping communities: 'we' as contemporary Europeans, 'we' as a nation, and 'we' as a community of heritage professionals (Kaasik-Krogerus 2020).

However, the EU officials and European panel members at the macro level and the sites and heritage practitioners at the meso level are not the only actors involved in politics of belonging. We argue that the visitors to the $\mathrm{EHL}$ sites participate in 'doing' European cultural heritage and imagining Europe at the micro level. In this chapter, we therefore analyze imagining Europe at the micro level in the EHL action, i.e. the visitors and their engagement with the Label. We explore how visitors to the EHL sites engage with the specific EHL discourse on Europe in terms of a 'politics of belonging' on the one hand and, on the other, how visitors perceive 'Europe' in this process. The interviews 
with visitors allow us to explore various constructions of Europe and multiple understandings of belonging and non-belonging to Europe from below.

In what follows, we first introduce the research data and methods used. Then, the empirical analysis consists of three parts: Europe of people; Europe of nations; belonging to Europe. We finish with conclusions on the multiple constructions of Europe and (non)belonging to it in the EHL context.

\section{Analyzing Europe from Below in the E HL Action: Research Data} and Methods

Our research is based on fieldwork at the EHL sites, which included visits, observations, and interviews with both visitors and heritage practitioners working there. In this chapter, we focus on the interviews with the visitors, examining 271 visitor interviews from $11 \mathrm{EHL}$ sites located in ten EU countries, which were conducted between August 2017 and February 2018 (see Chapter 1; Annex 1; Lähdesmäki et al. 2020). The interviews covered various topics, including the visitors' understanding of cultural heritage in general, European cultural heritage, 'Europe', European identity, and feeling European. The great number of interviews and the variety of interviewees make it possible to analyze how visitors from both $\mathrm{EU}$ and non-EU countries, and across different age groups, imagine, understand, and engage with Europe. Their responses help us to explore their personal views of Europe, of what constitutes the 'European' for them, and to interpret what specific experiences and attributes they relate with Europe. The qualitative interviews from the different sites enable us to analyze Europe from below, since they form discursive practices and subject positions in which people mobilize identities and a sense of belonging to explain, contest, or question the world around them (see also Wetherell and Potter 1992, 78; Siapera 2004, 131).

The visitors whose interviews are analyzed in this chapter include both EU citizens $(n=225)$ and non-EU citizens $(n=46)$. With the exception of one Russian, two Swiss, and two Ukrainian visitors, the non-EU visitors were not from member countries of the Council of Europe (see Annex 1). The EU visitors represented 19 nationalities, and we interviewed slightly more women visitors than men. Divided into three age groups, we had 98 younger visitors aged between 18 to 35 years, 112 visitors represented the middle-aged group (aged 36 to 65), and the group of older visitors (aged 66+) numbered 61 interviewees. The majority of interviewees had a higher (university) education, but others held diplomas from middle school, high school, college, and vocational school (see Annex 1). At some EHL sites, we interviewed many local visitors who lived 
near the site (e.g. Carnuntum Archaeological Park in Austria, Mundaneum in Belgium, or Robert Schuman House in France), while at others we met predominantly foreign visitors (e.g. Great Guild Hall, Estonia; Sagres Promontory, Portugal, and Franz Liszt Academy of Music and Memorial Museum, Hungary). The visitors' replies indicate that the vast majority of them were neither familiar with the EHL nor with the fact that the site they were visiting had been awarded it (see Čeginskas 2019). They had visited the sites for other reasons, such as leisure, vicinity, personal interest, and chance.

We conducted semi-structured qualitative interviews with the visitors. Depending on the length of answers, the interviews lasted from seven to almost 40 minutes. Since several researchers conducted the interviews at different sites, we agreed to keep the overall structure of the interview unchanged. However, depending on the interview situations, the actual order of the topics and themes varied from interview to interview, and sometimes required additional questions. In our analysis, we went through all the visitor interviews and focused on topics and themes related to interpreting European cultural heritage and European identity at the sites and in the exhibitions, and then analyzed the visitors' understandings of Europe, their (non-)belonging to Europe, and their feeling of being European. We used close reading and a qualitative content analysis of language use and discursive meaning making in our data. Consequently, our interpretations stem from our subjective readings and contextualizations of the data, which we addressed in joint discussions and intensive exchanges of views within our team of researchers.

The interviews engaged with people's perceptions of both the site and the notion of European heritage, which we understand as a dialogic process of meaning making between the visitors and heritage sites. We enquired how the interviewees engaged with the EHL and in this context perceived Europe and the EU (see also Lähdesmäki et al. 2020). The similarities and differences depicted in the process of close reading formed a basis for organizing the answers into specific categories (about the method, see also Kvale 1996, 192) for further analysis. The background questions about age, education, and nationality were mainly intended for constructing the social profile of the interviewees. In our analysis, the visitor interviews $(\mathrm{V})$ appear with a specific code that indicate the respective heritage sites $\left(\mathrm{S}_{1}-11\right)$, where the interviews were recorded, followed by a number that expresses the chronological order in which the interviews were conducted. For instance, vs3/11 refers to the eleventh visitor interviewed at Camp Westerbork. A more detailed overview of the EHL sites and their codes can be found in Annex 3 ; information on the social, educational, and ethnic backgrounds of the visitors to the sites is in Annex 1. 
In the interviews, we also asked the visitors about their associations related to the EHL logo and two of its slogans 'Europe starts here' and 'Europe starts with you' (see also Lähdesmäki et al. 2020). The former is the official slogan of the EHL, which is used for presenting the EHL action at all sites, with the exception of Camp Westerbork, which uses the slogan "Europe remembers Camp Westerbork". The slogan 'Europe starts with you' is found in the brochures and other promotional material informing interested heritage sites about the application aims and procedures. Both of these slogans are formulated by the Commission and used by the national coordinators of the action and the EHL practitioners at the awarded sites. The question about the slogans, thus, enabled us to explore the reception of the intertwined macro and meso-level EHL discourse at the micro level. During our interviews, most of the interviewees compared the slogans and usually preferred one to the other. Their interpretations of the slogans opened up a very interesting understanding about

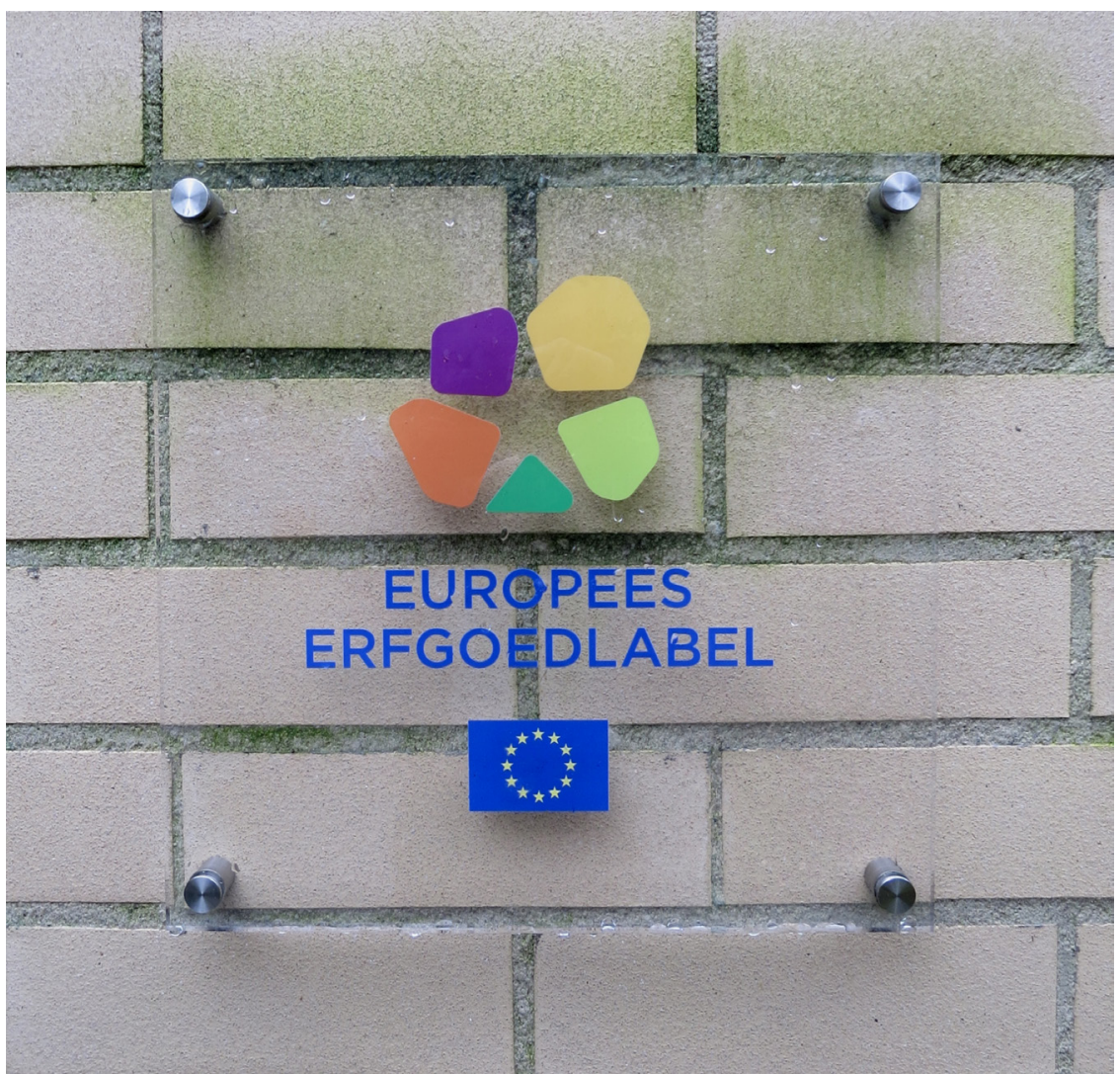

FIGURE 6.5 The EHL logo, photographed at Camp Westerbork, the Netherlands. PHOTO: EUROHERIT 
Europe based on location and/or individual disposition and participation. The simple and catchy formulations of the slogans provided a good basis for interpreting both the visitors' answers to their imaginaries of Europe and to questions directly connected with the EHL. During the process of data analysis, we realized the potential of the EHL slogans as a basis for discussing the EU's politics of belonging and decided to structure our chapter according to the 'Europe of people' and 'Europe of nations' positioned in the visitors' answers. It is important to emphasize that by analytically dividing the data, we do not intend to categorize visitors. As our data shows, interviewees gave controversial or multiple answers to the interview questions. The following sub-sections are mostly based on people's responses to each of the EHL slogans, whereas the third sub-section focuses on answers given about Europe throughout the interviews.

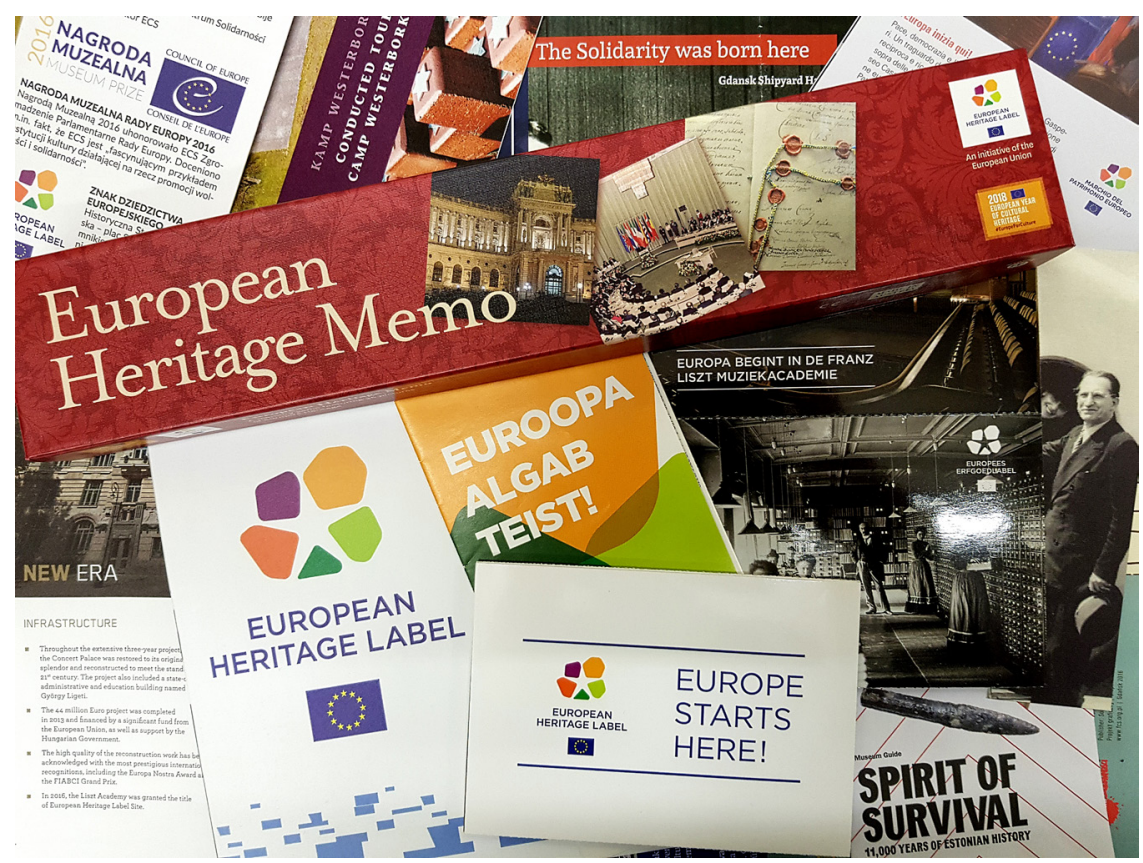

FIGURE 6.6 Collage of information brochures, flyers, and promotional material from various EHL sites and in multiple languages.

PHOTO: EUROHERIT

Various scholars have pointed out how the term 'Europe' is continuously 'owned' and used by the EU, its institutions and representatives, and they have explored how Europe is constructed in EU policies as a synonym for the Union (e.g. De Cesari 2017; Lähdesmäki et al. 2020; Turunen n.d.). The EHL is a good example of this common overlapping usage and understanding of the two 
entities. The questions we asked the visitors were affected by this conception. Since we asked about both the EU and the idea of European cultural heritage in the interviews, interviewees, partly unintentionally, intertwined Europe and the EU while elaborating on the EHL and Europe. Some interviewees claimed to be "European-minded" and "supportive of Europe" and explained that their "pro-European attitude" was linked to their studies of "European Law" or belonging to a generation "who believed in Europe" (e.g. vs3/3 and vs3/4). What these visitors meant is that they support the EU's politics and integration project. To tackle this phenomenon in our analysis, we use the term 'EUrope' for the cases where no clear distinction between the EU and Europe is made. As we explained in the introduction, this term combines 'Europe' the geographical continent and the political institutions and member states of the EU (see also Lähdesmäki et al. 2020).

\section{3}

\section{Europe of People: Europe Starts with You}

The analysis of the interview data showed that most visitors, both from the EU and outside, interpreted the EHL slogan 'Europe starts with you' as a mixture of possibility and responsibility. Feeling 'ownership' of Europe strengthened both people's personal agency and the idea that everybody is capable of contributing to Europe, to make it work. "If you want change, start with the man in the mirror," as one Dutch man in his fifties put it, referring to the EU $\left(v_{3} / 7\right)$. Some emphasized the individual approach and personal touch of the slogan (e.g. vs8/19; vs8/20), saying that it conveyed a sense of affiliation or solidarity and a participatory approach, which expressed an appeal of becoming active. This made the interviewees often feel personally addressed (e.g. vs2/12; vs2/13), something which we interpreted as engaging with the EHL's politics of belonging. As one of the interviewees claimed, the emphasis on 'you' made it clear that Europe is about people (vs2/17). Another interviewee, a retired German professor of law visiting Hambach Castle, suggested an understanding of Europe in terms of uniting people and creating a sense of community based on shared activities. Referring to the EHL slogan, he explained (vs7/15):

I mean, why would I want to juxtapose myself with others, instead of bringing them closer to me? Well, that's indeed a problem, I want everyone to be involved... It's rather "We are Europe", and we drive through Neustadt an der Weinstraße - of course, coincidences don't exist - and there, in the church, we experienced European youth playing music together. It was spectacular! There you could say "Europe starts with us" or "within us" - or something like that. 
This emphasis on people as actively participating in and being the essence of Europe renders the idea of EUrope a community that is both alive and in flux. A similar understanding of Europe and being European was reflected in the rejection and critical evaluation of the concept of identity that some visitors expressed, regardless of their gender, age, nationality, or visited heritage site. For them, the concept of European identity was too restrictive and carried excluding and static connotations with belonging. In their view, identity implied a rigorous understanding of belonging, based on distinguishing between those who are included and excluded, both physically and symbolically. For some visitors such an understanding came dangerously close to discourses about (racial) superiority and (national) exclusiveness. These visitors expressed the fear that a misuse of identity for political and nationalistic reasons could cause more harm than good. For instance, at Camp Westerbork, a Dutch visitor with a university degree in his early fifties explained (vs3/21):

I don't like the idea. We love discussing in the Netherlands about our identity. I think it's a dangerous idea of trying to formulate an identity on the level of a nation or the level of a continent.

A Belgian visitor in her late forties at Mundaneum explained that the use of the concept of identity in connection with Europe raised uncomfortable feelings in her; in contrast, she perceived 'culture' as an enclosing concept that enabled a broader sense of commonality between people (vs9/22):

Because the name, the word, 'identity' sounds to me like something that is inclosing people, that is just, you know, yeah, closing doors. It is 'MY identity' and if we need a 'common identity' - it means that we have to accept people in, or they are out. And that is something that is quite sad. While culture is not like that. Culture is like a common ground.

Besides identity, the concept of Europe(an) as a fixed and closed entity was criticized by some visitors, since it "is not good to create divisions", as a young Polish woman put it (vs8/19). These interviewees defied clear boundaries of what and where Europe is or why Europe has to 'start from here' (e.g. vs3/29; vs3/3o; vs2/2). For instance, a man in his early fifties of Belgian origin, who had lived and worked for many years on other continents, elaborated at the Mundaneum: "Where does Europe end? Humanity is arbitrary anyway. So, where does Asia begin, where does Europe begin? Well, there is an ocean next to it, but I mean, it's a continent" (vs9/27).

Against this criticism of defining clear territorial boundaries of Europe, many of the interviewees consistently pointed out that the experience of 
mobility was one of the key reasons why they felt European and had a sense of belonging to Europe. The important role of mobility and free movement for European integration has been noted elsewhere (e.g. Favell 2008; Recchi and Favell 2009; Favell and Recci 2011). In our data, mobility was connected to free movement and travel across borders within Europe. It was also about being able to talk and communicate with fellow Europeans, share common interests and concerns, and, in a quite literal and practical sense, directly get in touch with them. Many interviewees spoke of their own mobility experiences, which had led to their meeting, exchanging views, or forming personal relationships and friendships with other Europeans. These experiences led some interviewees to argue for a common awareness as Europeans and construct belonging to EUrope in emotive ways, despite their simultaneous observation of existing linguistic, cultural, historical, and geographical differences. Such intertwined experiences of mobility and encounter seemed to reduce the 'felt' distance between Europeans of different national, regional, or cultural backgrounds.

Scholarly discussions highlight the fact that people need enough money and valid passports or identity cards in order to benefit from 'borderless Europe' (see also Rumford 2008, 41-42; Lähdesmäki et al. 2020). The interviewed visitors did not mention this, but conveyed the impression that mobility was a normal condition and taken-for-granted practice in contemporary EUrope. Visitors referred - explicitly or not - to institutional developments in the EU in recent decades, such as the Schengen Agreement, which opened borders and enabled free movement of people, capital, goods, and services within this space. Other important aspects mentioned in this context were the harmonization of regulations and services in connection with the single currency (the Euro) or mobile data roaming. Thus, the interviewees referred to the construction of a common European space that encouraged unlimited personal mobility within it, and referred to political processes that helped to connect member states and spread ideas and phenomena all over EUrope. For instance, a German woman in her late forties visiting Robert Schuman House in France explained (vs10/14):

I mean, I have the impression that I benefit from the way in which Europe is today, that's how I experience it. For example, I can freely move across borders, or these small everyday advantages, like the common currency, which is really very useful here in the borderland. [...] So, I find it very useful in everyday life, especially if you live here. I find it very nice that it is in general possible to move from one country to another without problems. 
Like many other visitors, this interviewee equated Europe with (the Schengen area of) the EU, in which the borders between the member states have become invisible. Some other visitors constructed Europe as a shared space based on their educational and professional experiences (gained e.g. through Erasmus, other university or school exchange programmes, or working abroad or in international environments) as well as their personal opportunities for leisure travel. A young French student described her perception of Europe as follows (vs4/4):

It is to be able to speak with English people, Germans... lots of countries of Europe. And to have common things in the sense that we all belong to the European Union. We can freely travel from one country to another without necessarily crossing any real border. That's it. It is freedom of exchange, of expression between all the member countries. And to know that we are, so to speak, 'allied'. We are all together reunited around the EU.

EUrope as a common space constituted by mobility becomes associated with a feeling of connecting with people, friends, and family members across Europe. A man in his early fifties visiting Hambach Castle highlighted the relevance of cultural and real experienced mobility by reflecting on his personal situation (vs7/19):

Yeah, first, we have this partnership, he is Flemish, I am German. I have Finnish roots; my mother is Finnish. So, it was always about different cultures and identities at my home, however, rather European-American.

A sense of belonging to Europe was strengthened by travelling not only within, but also outside the EU, especially to other continents. Ideas about the 'other' did not emerge from juxtaposing one European state against another but rather from identifying Europe's 'other' and locating it to Africa, Asia, America, Australia - places that were further away than a neighboring European state, and separated by geographical distance and boundaries. In this context, "being European' was seen as having "always been different from the way of being African, the way of being Asian, the way of being American" (vs1/9). The visitors often perceived the difference between Europe and other non-European places as 'real'. As a Dutch woman in her late forties argued, it was easier to feel "at home" in different places across Europe than in Asia, Africa, or America, increasing the perception of a unity among Europeans (vs3/27). Other 
interviewees explained that travelling and staying outside Europe felt different because of the unknown currencies, cultural practices, or language (e.g. vs6/19; vs7/12; vs9/7; vs9/23; vs9/28). For some visitors, this difference in the perception between European and non-European countries served as proof of the existence of a common European culture (vs9/23). As one Belgian man in his late forties at the Mundaneum put it (vs9/7):

Once we go beyond, as I said, Europe, and we get to, be it in Asia... or the United States, America. North America, South America: You travel enormously, you see at once that they have another identity, another culture.

Similarly to the visitors from EU countries, those from non-EU countries referred to mobility as a main aspect of what defined today's EUrope. As a young PhD student from the US, visiting the Great Guild Hall in Estonia, confirmed, "[b]ut if there's one kind of [common] thread through all of them, it would be the four principles [freedoms of movement] that are kind of stated in the EU's charter, and the concept of solidarity is very important" (vs6/18). Some visitors from outside the EU used mobility to boost their case for constructing a personal connection with Europe. They often interpreted the mobility of their ancestors from various parts of Europe to the USA, Canada, Australia, New Zealand, or South America as something that enabled them to imagine Europe as a specific community that they could engage with because of their heritage and 'roots'. For instance, a US visitor to the Great Guild Hall in Estonia explained that his "great-grandparents came from Germany and Wales, and I grew up in a city that was predominantly German, very German. So, I've always had a sense of connection back with Europe" (vs6/2). However, in some cases, this imagined link with Europe based on roots and shared culture went beyond the idea of forming a community only with EU citizens. As a Chilean visitor to the Carnuntum Archaeological Park, a man in his fifties, argued (vs2/2):

if the culture that passed on to your parents is of European roots, then that's European heritage. So, it doesn't have to be only Europe, within the continental European mass, but it could be maybe from somebody from Australia that might have identity with us. [...] Because I was raised with very strong Spanish values, and always reminded in Chile, being a country, which is itself multiracial, I was always reminded that this is your background, it's... mostly, mostly Spanish, yeah.

As these quotes show, mobility was largely understood as positive: the vast majority of the visitors related it to the wider context of modernity and their 
own (rather privileged) position in this world. Mobility implies the potential to create new connections, which does not necessarily need to be restricted to Europe but may help to construct an imagined community with different people in various places. However, not all visitors shared such an 'unproblematic' view of mobility. For instance, some visitors interviewed at Camp Westerbork saw people's forced mobility during World War II as a warning example for today. Similarly, at the Great Guild Hall in Tallinn, where the permanent exhibition displays the harsh conditions, violent conquests, and foreign rule throughout Estonian history, some visitors widened the concept of mobility. They discussed critical issues connected with mobility, including deportations and fleeing wars in the past, but connected these to life in the world today. While visitors addressed the current solidarity crisis among EU member states about receiving refugees from various (mainly non-European) countries, they often approached mobility as a political and humanitarian challenge. Some saw it as a security problem for contemporary Europe - not necessarily taking into account the refugees' perspective on the trauma of forced migration.

The interviewed visitors frequently interpreted the EHL slogan 'Europe starts here' in both spatial and temporal terms. Their understanding that Europe was linked with certain personalities and started with a specific event or at a particular geographical point corresponds to how the EHL action and the awarded sites present Europe and European cultural heritage. These interpretations had one thing in common: understanding Europe as an entity consisting of bounded geographical areas with cultural characteristics considered as 'European'. At sites like Alcide de Gasperi House Museum or Robert Schuman House, visitors mentioned the role that its 'Founding Fathers' had played in the establishing the EU. Similarly, the visitors to Carnuntum - a site that is dedicated to the Roman past - created a connection between the Roman Empire and contemporary Europe (e.g. vs2/1). Some visitors explained their European belonging by referring to the towns or regions where they lived; others perceived themselves as European as their "country is European", as a Slovak visitor to Carnuntum simply put it (vs2/1). The visitors interviewed in Tallinn, Estonia, and Sagres, Portugal, referred to the specific geographical location of both sites at the 'spatial edge' or political border of the EU (e.g. vs6/2; vs11/8). Similarly, visitors to sites that were situated in national border areas often emphasized the meaning of borders and the experience of transgressing them, as for instance at Hambach Castle (Germany), Mundaneum (Belgium), Carnuntum 
(Austria), Lieu d'Europe (France), Alcide de Gasperi House Museum (Italy), and Robert Schuman House (France).

Hence, these visitors contextualized Europe by entangling local, regional, national, and European scales, which allowed them to claim belonging to Europe alongside sensing belonging to their home country, nation, region, and town. In this respect, the visitors' sense of belonging closely resembled the 'marble cake' model, in which culturally diverse states constitute 'Europe', and their community within the EU determines and conditions citizens' belonging to EUrope (Risse 2004, 251; see also Breakwell 2004). However, the role of the individual citizen is rather limited in such a 'Europe of nations', since their agency is largely tied to, and thus subordinate to, the agency of the state. This means that Europe is imagined as a normative community (the EU) with specific 'rules and regulations' that bind together different states and thus the people who live there. However, the normative character neither abolishes existing controversies between European countries or cultural communities, nor renders 'Europe' uniform. As the interview data from the EHL sites shows, visitors from both within and outside the EU alike imagine such a 'Europe of nations' as a culturally diverse community united by shared values.

The visitors commonly understood Europeanness in terms of a strong sense of spatiality, which enabled them to feel a sense of connection to and draw a distinction between different places at the same time. The majority of the visitors greatly valued the cultural and national differences inside the EU and regarded them as worth preserving. Several visitors claimed: "When I think about Europe, I think about all different kind of cultures everywhere. That it's actually good" (vs6/13, Dutch man under 25); or argued: "I mean there are different cultures, too, in parts of Europe and in knowing that it's still Europe, so it's important to keep this parity" (vs11/28, young French woman). Some visitors emphasized that Europe created a common cultural space consisting of differences based on the diversity of culture and heritage in the various European countries (e.g. vs9/16, Belgian woman under 25; vs8/18, Polish woman in her early thirties). Hence, different languages, peoples, cultures, states, and landscapes are viewed as decisive and defining aspects of Europe, as outlined for the ECC project in Chapter 5 . In the words of one visitor, Europe is both "multicultural" and "rich" (vs10/9, French man in his fifties), and unites diverse elements: "As if Europe is one, but it consists of different elements, regions that have their own characteristics" (vs8/18, young French woman). Visitors from both EU and non-EU countries described Europe in similar ways as being different, diverse, manifold, progressive, possessing common goals, and a place where no animosity existed between neighbors (e.g. vs11/32; vs11/33), thereby often overlapping with the EU narrative. As a visitor from Canada claimed: 
"I mean it's a real mix of cultures, Europe, from the Scandinavian countries through the Baltic, through the Iberian Peninsula, all different. Italy's different, France - European culture is a blend of all of that to me." (vS11/13).

In some cases, the discussion of Europe's cultural richness developed into admiring its perceived cultural uniqueness. Eurocentric views emphasized the superiority of Europe, too. Visitors from both inside and outside the EU held these views. Visitors from the USA, Canada, and Australia, in particular, tended to construct an "Old World" discourse that underlined the Europe's cultural richness, long history, and great cultural heritage compared to their home countries. After her visit to the EHL site in Hungary, an American woman in her mid-eighties described Europe as the "predecessor to the new world. We all come from here, although some come from Asia, but the majority come from the whole Europe, to America, to the new world" (vs5/13). Another American man of the same age, interviewed at the Great Guild Hall in Estonia, explained: "We in America look at anything 300 years old is really, really old. Really old. In fact, I happen to live in one of the oldest towns in America. We were founded in 1638. For you that stuff is all over the place here, it's twice that old" (vs6/9). The visitors' discourse contributed to reinforcing the narrative of Europe's cultural diversity and historical cultural richness at the expense of the cultural richness of other cultures and communities, such as the native first nations in the USA and Canada or the Aborigines in Australia.

The temporal aspect of 'Europe starts here' was strongly related to values stemming from the past that many visitors regarded as being supposed to unify the culturally diverse European countries. As a young French couple interviewed together at Lieu d'Europe in Strasbourg, France, pointed out, although each European country has a different culture, history, and identity, "we still share the same values" (vs4/4; vs4/5). The EHL documents refer to "freedom, democracy, respect for human rights, cultural and linguistic diversity, tolerance and solidarity" as the core values of the EU (EP\&C 2011, 1), and unsurprisingly, the visitors, like the participants in the ECOC project (see Chapter 4), point out the same intangible meanings and universal values. The visitors referred to values such as "tolerance, freedom, independence, history, learning from history" (vs2/9, Austrian woman in her early fifties), "understanding for others" (vs2/13, Austrian man in his early forties), the "rule of law" (vs2/11, Austrian man in his late thirties) and "democracy" (vs8/13, man from the UK in his twenties). Interviewees also frequently mentioned freedom, equality, peace/maintaining peace, human rights, and openness, while some connected well-being and welfare with the construction of a social Europe ( $\left.\mathrm{vs}_{4} / 2 ; \mathrm{vs}_{4} / 3\right)$. For instance, one Austrian woman visiting the Carnuntum Archaeological Park explained (vs2/9): 
I think Europeans, no matter where they are from, from the West or from the East, we all have... well, history has basically moved across the whole continent through all centuries and millennia. And in my opinion what makes us today European, is that - that we fought for our freedoms, for tolerance, equality of women, and religious freedom.

Several interviewees also referred to the EU as a peace-project, creating thus a close link between Europe and the EU, like a young male visitor at the Alcide de Gasperi House Museum (e.g. vs1/13). The same young Italian visitor also cautioned that we should not take these values for granted due to Europe's past conflicts, including World War II, the time of the Iron Curtain dividing Europe into 'East' and 'West', and before the creation of the EU. In his opinion, "the aim of Europe" is based on "equal principles: that of freedom, of guaranteeing culture, of guaranteeing healthcare, and therefore the theme of citizens' rights" (vS1/13), which need to be safeguarded. Many visitors at different sites repeated the EHL rhetoric of learning from the past and stressed that it was important to ensure that 'these times will never come back'. This reference to the past arose again when some visitors discussed the future of Europe in terms of maintaining what 'we have achieved'. This type of rhetoric is a good example of identifying with EUropean narratives and connects to the issue of dual loyalty between the national and European: whether a person identifies more strongly or frequently with local, regional, national, or international (including European) communities (see also Hermann and Brewer 2004, 12).

In the interview data, some visitors elaborated on the controversies between cultural diversity and the notion of a common Europe. Europeanness was sometimes interpreted as threatening to homogenize the particularity and originality of national cultures in Europe. Yet other visitors underlined how different nations, languages, cultures, and people complicated the formation of a common Europe. For instance, a middle-aged German visitor to Hambach Castle argued (vs7/8):

Yeah, I think it can't work with all these different cultures, different languages to have one Europe, like being one country... It's good that there is a European community for sure, 'cause we never had that long time of peace, I think. So, it's good to, that it's there, but it's not... you cannot understand it as being one country.

Various interviewees claimed that they felt national, in terms of being "more Poles than Europeans" (vs8/14, Polish woman) or did not feel European "as 
strongly as I feel Dutch." (vs3/1, Dutch woman) whereas some 'chose their sides' and identified only with the nation state (e.g. vs $3 / 5$, Dutch man in early thirties) or only with Europe (e.g. vs2/18, Czech woman in her late sixties). This indicates that people have multiple and highly varied priorities as regards national and European belonging (see also Citrin and Sides 2004, 164). However, while right-wing parties appropriate the 'Europe of nations' as a positive identity for their own agenda, to distinguish it from the EU and EUrope as a negative identity (see also Niklasson and Hølleland 2018; Lähdesmäki $2019 \mathrm{~b}$ ), in our data these two were considered as complementary rather than contradictory.

\section{$5 \quad$ Belonging to Europe: From Purposeful Vision to Banal Normality}

During the interviews, we asked visitors about their social backgrounds, including their nationality, level of education, country of residence, and age. Distinguishing between non-residents/tourists and EU citizens/residents of EU member states, our data shows that the vast majority of the interviewed visitors sensed belonging to Europe. While the interviews did not include any questions on the EU, the visitors often brought up their - mostly positive - associations with Union. Only a small minority felt negative or a lack of belonging to EUrope. As the visitors engaged in various ways of imagining Europe and constructing belonging and non-belonging, nationality and country of residence did not appear to strongly influence their answers. Similarly, we did not see a marked difference in answers based on the interviewees' gender. As regards their educational background, our data confirmed that people with higher education (a college degree or higher), had only positive associations with Europe and the EU. However, there is a strong bias in our sample towards higher-educated interviewees (see Annex 1); most of them held at least a college degree or were students. Among those with lower levels of education, both sentiments (e.g. approval/disapproval of Europe; belonging/ non-belonging to Europe) were almost equally represented. In short, nationality, residence, gender, and education may have affected some narrations and views on Europe, the 'European', and belonging, but were neither the most decisive nor the most conclusive factors in constructing interviewees' views. However, age proved significant for constructing specific narratives and notions of belonging (see Chapter 7 ). We divided our data into three age groups: (1) older visitors (aged 66+), (2) middle-aged visitors (36-65), and (3) young visitors (aged 18-35). With a few exceptions, the visitors' responses on 
belonging were somewhat similar within these age groups. We now focus on the predominant views about Europe, the 'European', and notions of belonging to Europe that we found in these three age groups.

The visitors belonging to the older generation most frequently referred to peace as the most important motive for sensing and working towards European belonging. As many of them still remembered the destruction and the process of rebuilding society and infrastructure in the decades immediately following World War II, they often claimed to have a personal interest in belonging to Europe for maintaining peace and developing closer collaboration between Europeans.

Older visitors believed it was possible to achieve imaginary unity with other Europeans based on shared historical experiences, which included the 'utilitarian' function of the EU in creating peace and prosperity, as this older German visitor to Hambach Castle explained (vs7/4):

When I was born and a child during the war, I witnessed the bombings, and if I count back as a historian how many peace gaps were there between each war, then I have to say that Germany, we, never did better, based on this development.

This group of visitors often stressed that people across different European states shared a common vision of creating peace and sustainable development. The visitors explained that they personally believed in and were convinced of the particularly political and economic necessity of the European project, which remained a legitimate way of providing more opportunities and creating a peaceful stability despite the cultural differences and the problems between European nation states. For instance, an older Italian man argued that "at the political level, it's important to try to reason because divisions are never good for anyone and this is what we learn from history" (vs1/10). Likewise, a French visitor to the Franz Liszt Academy of Music spoke of Europe as a "communed continent, a communauté" making it possible "to build something together, in order to remove the conflict and also in order to be more powerful against the other economic systems". He continued that when he was young "we were really into it, and now, personally, I'm surprised by the discussion and so on, and including my children" who seemed to be more critical towards belonging to EUrope (vs5/5).

While the experience of mobility was less of a personally decisive factor in their sense of belonging to Europe, the older generation recognized and highlighted mobility as a decisive factor in creating opportunities for younger people to share ideas and practices and to develop a sense of commonality. 
Two elderly French women (vS10/20 and vs1o/21), who were jointly interviewed and mutually completed their thoughts at the Robert Schuman House, expressed a clear connection between sensing belonging to EUrope and the experience of mobility:

- It's a mixture of all the people, all these students who go and study in Spain, go on exchanges, the Erasmus programme, and all that.

- There is a lot of exchange now.

- There is a lot of exchange...

- When you see the young people...

- ...at university level and all that. It's very good.

In contrast, the group of middle-aged visitors were often more critical of the idea of creating a shared European belonging. They shared with the visitors in the older generation an approach to Europe that was closely intertwined with the developments of the EU. Frequently, they referred to their sense of Europeanness in terms of the added value of being part of the EU, in terms of a functional sense of belonging: the $\mathrm{EU}$ is beneficial for the individual but also for the state in which the individual lives. In other words, the visitors recognized the utility of the EU as it offers a structure that helps unite and form a community to face economic, political, environmental, and other challenges collectively in today's globalized world but beyond this, they often lacked a personal approach towards Europe. As a middle-aged French woman at the Robert Schuman House pointed out (VS10/3):

We are nevertheless anchored in our language, our heritage as well, everything that represents culture, so well... what's more European for me is the currency. It's this freedom now... in any case I feel as I do, having known the franc. [...] Even if you go over the German or English border, or if you go to other countries, the Euro is accepted and exchanged anyway, but indeed it's a great freedom, additionally to the freedom of movement.

The group of middle-aged visitors did not witness the reconstruction of states after World War II, but their generation was familiar with the European integration process (e.g. the introduction of a common currency) and their countries becoming part of the European Community and/or the EU. They grew up in a time when the EU focused its efforts on expanding its ideas and policies in the member states and created the motto 'united in diversity' to bridge cultural and national gaps. While visitors in this age group shared memories of the transformation from national currencies to the Euro, which for some 
involved ambivalent experiences, unlike the older generation, they did not share personal recollections or memories of the immediate post-war period. The middle-aged visitors referred to the peace narrative in their discourses, but they were not necessarily able to connect or construct a personally meaningful memory of it as it was too distant from their own lives.

Although some referred to shorter school exchanges, the majority of this age group had not personally benefited from longer stays abroad, unlike many of the younger visitors. However, this does not mean that they were not mobile. Many middle-aged visitors had travelled and their answers expressed a great appreciation of cultural differences in Europe, which they had encountered on their travels and which they considered to constitute the essence of Europe. Based on their experiences, cultural diversity, in particular the lack of a common European language, was nevertheless viewed as an obstacle to creating a sense of belonging to Europe, as a German woman in her late forties explained (vS10/14):

Well, I think the European identity is essentially nourished by this diversity. I mean that we have different regions with different traditions, languages, foods, clothing, whatever, and that it combines this diversity. [...] Well, I think it [European identity] can only develop for real if everyone had a second, I mean for the most of us a second, additional official language, and nowadays that's only English.

As a result, many visitors in this age group were skeptical about the possibility of constructing European belonging as, in the words of a Dutch man, "the interests in southern Italy are very different from the interests of northern Norway, just to give an example. The distances are too big" (vs3/12).

On the contrary, young people who grew up as EU citizens benefited of the experience of open borders and mobility. Such experiences were often part of their ordinary life and everyday practices and therefore taken for granted (see also Chapter 5). The young interviewees were often familiar with passport controls, border checks or currency exchanges in different European states only as stories told by their parents and grandparents, and in exhibitions. One young German visitor to Lieu d'Europe spoke of Europe as "sort of instinctively part of my identity, more on a day-to-day basis" (vs4/17) upon which she did not need to reflect. She explained (vs4/17):

I grew up with the Euro, I mean. I think I was like eight, when we got the Euro starter kit and we were all standing around the kitchen like "oooh". Yeah, but having the Euro, being able to travel, being part of the Schengen 
zone, never needing a visa, being able to do Erasmus, these are things that come very natural to me, and therefore I would always intuitively say that I'm European without having to reflect hard or having to adapt to new circumstances. I just grew up in this environment, so it's part of who I am and how I perceive my environment.

Visitors belonging to this younger age group often referred to bottom-up experiences of being European through participating in longer exchanges and mobility (e.g. the Erasmus Programme), which influenced their perception of Europe and their emphasis on sharing commonalities in Europe despite observing and experiencing cultural differences. Similarly, they did not think about belonging in the same national categories as middle-aged interviewees, tied with language, territory, or nationality. As one young Belgian interviewee explained, "Let's say that we stay human, no matter what happens. As for the rest, it varies" (vs9/11).

Young visitors often referred to common values when discussing Europe, the 'European', and belonging to Europe. As a young Italian student (Vsi/11) at the Alcide de Gasperi House Museum explained, Europe constituted "[d]iversity of culture and the respect of culture, liberty, democracy. Differences from a cultural point of view and in particular the respect of other cultures, other people, other nations". However, for the visitors in the youngest age group, values were not the most dominant aspect of their notions of and relations to Europe. References to values were frequently linked to concrete political provisions and actions - like the Schengen area or the Eurozone - that contributed to constructing a taken-for-granted Europeanness among many of the younger visitors. However, for some, Europeanness was not an individual choice but something they had inherited by birth, as a young French student put it: "Yes [I feel European], after all, we were born in Europe" (vs10/10). Among these interviewees, the conflation between Europe and the EU became obvious. When asked whether and why they felt European, a young Austrian couple (he was a carpenter, she a student), simply answered: "Because I was born here (vs2/15); Yes" (vs2/14). To a certain degree, such answers show how Europeanness may be commonly perceived through contemporariness - as a sense of belonging shaped by interaction with people in the present and in relation to dominant discourses (see Chapters 4 and 5 ).

The conception of a 'day-to-day European reality' or the experience of Europe as a 'normal entity', as revealed in the answers of the youngest age group, is the key aspect of a 'Europe of people'. This conception is formed by the social, economic, and political benefits of EU integration for the individual. Drawing on Billig's (1995) concept of 'banal nationalism', Cram (2009, 110, 114; 
2012,83 ) suggests that everyday practices and daily encounters with Europe's symbols produce banal, serendipitous, and contextual processes that facilitate unconscious identification with EUrope (see also Deutsch 1966, 117; Billig 1995, 42; Sassetelli 2009). The perception of a 'European reality' relates to the development and implementation of EU-wide binding policies and norms in the framework of European integration (see Risse et al. 20o1; Trenz 2015). This makes it possible to understand the EU visitors' belonging to Europe in terms of manifold processes and engagements with Europe in the everyday, and may increase their sense of belonging to Europe. Mobility is one significant factor in imagining EUrope as a space and community of possibilities, whereas controversial issues are frequently left out of the scope of this everyday belonging. European visitors also confirmed that with geographical distance, the idea of being European was more accepted, as the term 'European' was better recognized from outside than within specific European states. Unlike 'Europe', which commended itself as a 'brand', neither 'Austria' nor 'Austrian', sparked immediate associations outside Europe, as a male Austrian visitor in his twenties noted at Carnuntum (VS2/20).

According to some scholars (Mummendey and Waldzus 2004, 69), a sense of belonging to Europe may increase commonality and tolerance between Europeans at different levels. The fact that people from outside Europe perceive Europeans as somehow similar and representing one entity, despite their cultural and historical differences, facilitates the construction of a shared sense of belonging to Europe. As our study highlights, there are several 'Europes' depending on who you ask, and it is therefore important to consider in which contexts these 'Europes' occur and are constructed. At the same time, the concept of Europe is often perceived as vague. In our data, the visitors both from EU and non-EU countries wondered whether the concept referred to a geographical (the continent) or a political and economic entity (the EU), whether Europe had to be understood in cultural terms (referring to the experience and knowledge of historical, cultural, and linguistic diversity), or whether Europe was defined by their personal experiences. When engaging with the politics of belonging of the EHL, Europe, the EU, European identity (least by the fact of EU citizenry), and European cultural heritage all seemed to become intermingled and intertwined.

Visitors referred to cultural diversity as a defining feature of Europe in almost all interviews. The EU motto 'united in diversity' hence described the 
notion of belonging and attitudes of many visitors to the EHL sites in our study (see also Lähdesmäki et al. 2020). Thus, the macro- and micro-level discourses on Europe seemed to include similarities. As our analysis showed, the interviewees' notions of Europe resonated with how the EU defines itself. The EU value discourse found its way into almost all our interviewees' answers about European values, albeit in an indefinite way. While lack of concreteness in a discourse is often perceived as a shortcoming, it can also help to strengthen the reception and adoption of a discourse by a broader public. Although the values discourse remains vague and contains a variety of interpretations and understandings, at the same time it can give people the impression of sharing 'something' in common. Commonality is often constructed through narratives of personally meaningful experiences. The interview data shows that being able to understand and imagine Europe in multiple ways enables different people to engage with EU's politics of belonging, and the reverse is also true: the EHL as politics of belonging associates with different understandings of 'EUrope'. Through its emphasis on a European dimension, the EHL enables a transnational interpretation of cultural peculiarities, similarities, and commonalities. Furthermore, immaterial aspects of the heritage awarded with the EHL make it easier for different groups and individuals to identify with this heritage.

\section{References}

Billig, M. 1995. Banal Nationalism. London, Thousand Oaks and New Delhi: Sage.

Borgmann-Prebil, Y., and M. Ross. 2010. "Promoting European Solidarity: Between Rhetoric and Reality?" In Promoting Solidarity in the European Union, edited by Y. Borgman-Prebil and M. Ross, 1-22. Oxford: Oxford University Press.

Breakwell, G. M. 2004. "Identity Change in the Context of the Growing Influence of European Union Institutions." In Transnational Identities. Becoming European in the $E U$, edited by R.K. Hermann, T. Risse, and M.B. Brewer, 25-39. Lanham, Boulder: Rowman \& Littlefield Publishers.

Čeginskas, V. L. A. 2018. "The Added European Value of Cultural Heritage. The European Heritage Label." Santander Art and Culture Law Review 21 (4): 29-50.

Čeginskas, V. L. A. 2019. "The Challenges in Creating Visibility of European Cultural Heritage: A Case Study of the European Heritage Label." Ethnologia Fennica 46: 109-134.

Čeginskas, V. L. A., and S. Kaasik-Krogerus. 2020. "Politics of Solidarity in the Context of European Heritage. The Cases of the European Solidarity Centre and Hambach Castle." International Journal of Heritage Studies 26 (10): 998-1012. doi: 10.1080/13527258.2019.1663235 
Citrin, J., and J. Sides 2004. "More than Nationals: How Identity Choice Matters in the New Europe." In Transnational Identities. Becoming European in the EU, edited by R.K, Hermann, T. Risse, and M. B. Brewer, 161-185. Lanham, Boulder: Rowman \& Littlefield Publishers.

Cram, L. 2009. "Identity and European Integration: Diversity as a Source of Integration." Nations and Nationalism 15 (1):109-128. doi:10.1111/j.1469-8129.2009.00367.x

Cram, L. 2012. "Does the EU Need a Navel? Implicit and Explicit Identification with the European Union." Journal of Common Markets Studies 5o (1): 71-86.

De Cesari, C. 2017. "Museums of Europe: Tangles of Memory, Borders, and Race." Museum Anthropology 40: 18-35.

Deutsch, K. 1966 [1953]. Nationalism and Social Communication. Massachusetts: MIT Press.

EC (European Commission). 2010. Proposal for a Decision of the European Parliament and of the Council Establishing a European Union Action for the European Heritage Label. COM (2010) 76 final, 2010/0044 (COD). Brussels: European Commission.

EC (European Commission). 2011. European Heritage Label. Guide for Candidate Sites. European Commission 2011, Brussels.

EC (European Commission). 2016. European Heritage Label. Panel Report on Monitoring. 19 December 2016. Brussels: European Commission.

EC (European Commission). 2017. European Heritage Label. 2017 Panel Report. 5 December 2017. Brussels: European Commission.

EP\&C (European Parliament and the Council). 2011. "Decision No 1194/2011/EU of the European Parliament and of the Council of 16 November 2011 establishing a European Union action for the European Heritage Label." Official Journal of the European Union L 303: 1-9.

Favell, A. 2008. Eurostars and Eurocities. Free Movement and Mobility in an Integrating Europe. Malden: Blackwell Publishing.

Favell, A., and E. Recchi. 20og. "Social Mobility and Spatial Mobility." In Sociology of the European Union, edited by V. Guiraudon and A. Favell, 50-75. Basingstoke: Palgrave Macmillan.

Hermann, R., and M. B. Brewer 2004. "Identities and Institutions: Becoming European in the EU." In Transnational Identities. Becoming European in the EU, edited by R. K. Hermann, T. Risse, and M. B. Brewer, 1-22. New York: Rowman \& Littlefield.

Kaasik-Krogerus, S. 2019. "Politics of Mobility and Stability in Authorizing European Heritage: Estonia's Great Guild Hall.” In Dissonant Heritages and Memories in Contemporary Europe, edited by T. Lähdesmäki, L. Passerini, S. Kaasik-Krogerus, and I. van Huis, 157-181. New York: Palgrave Macmillan.

Kaasik-Krogerus, S. 2020. "Identity Politics of the Promotional Videos of the European Heritage Label." Contemporary Politics 26 (1):1-16. doi:10.1080/13569775.2019.1611207 
Kohli, M. 200o. "The Battlegrounds of European identity." European Societies 2 (2): 113-137.

Kvale, S. 1996. InterViews: An Introduction to Qualitative Research Interviewing. Thousand Oaks: Sage.

Lähdesmäki, T. 2014. "The EU's Explicit and Implicit Heritage Politics." European Societies 16 (3): 401-421. doi: 10.1080/14616696.2014.894547

Lähdesmäki, T. 2016. "Politics of Tangibility, Intangibility, and Place in the Making of European Cultural Heritage in EU Heritage Policy." International Journal of Heritage Studies 22 (10): 766-780.

Lähdesmäki, T. 2019a. "Founding Myths of EU Europe and the Workings of Power in the EU Heritage and History Initiatives." European Journal of Cultural Studies 22 (5-6): 781-798.

Lähdesmäki, T. 2019b. "European Culture, History, and Heritage as Political Tools in the Rhetoric of the Finns Party." In European Memory in Populism, edited by C. de Cesari and A. Kaya, 191-209. London: Routledge.

Lähdesmäki, T., Kaasik-Krogerus, S., and K. Mäkinen. 2019. "Genealogy of the Concept of Heritage in the European Commission's Policy Discourse." Contributions to the History of Concepts 14 (1): 115-139.

Lähdesmäki, T., V. L. A. Čeginskas, S. Kaasik-Krogerus, K. Mäkinen, and J. Turunen. 2020. Creating and Governing Cultural Heritage in the European Union: The European Heritage Label. London: Routledge.

Mummendey, A., and Waldzus, S. 2004. "National Differences and European Plurality: Discrimination or Tolerance between European Countries." In Transnational Identities. Becoming European in the EU, edited by R.K. Hermann, T. Risse, and M. B. Brewer, 59-72. New York: Rowman \& Littlefield.

Niklasson, E. 2017. "The Janus-Face of European Heritage: Revisiting the Rhetoric of Europe-Making in EU Cultural Politics." Journal of Social Archaeology 17 (2): 138-162. doi: $10.1177 / 1469605317712122$

Niklasson, E., and H. Hølleland. 2018. "The Scandinavian Far-Right and the New Politicization of Heritage." Journal of Social Archaeology 18 (2): 121-148. doi: 10.1177/ 14696o5318757340

Recchi, E., and A. Favell, eds. 2011. Pioneers of European Integration. Citizenship and Mobility in the EU. Cheltenham: Edward Elgar Publishing Inc.

Risse, T. 2004. "European Institutions and Identity Change: What Have We Learned?" In Transnational Identities. Becoming European in the EU, edited by R. K. Hermann, T. Risse, and M. B. Brewer, 247-271. New York: Rowman \& Littlefield.

Rumford, C. 2008. Cosmopolitan Spaces: Europe, Globalization, Theory. London: Routledge.

Sassatelli, M. 2002. "Imagined Europe. The Shaping of a European Cultural Identity through EU Cultural Policy." European Journal of Social Theory 5 (4): 435-451. 
Sassatelli, M. 20o9. Becoming European. Cultural Identity and Cultural Policies. Basingstoke: Palgrave Macmillan.

Siapera, E. 2004. "EU Correspondents in Brussels: Between Europe and the NationState." In Transnational Identities. Becoming European in the EU, edited by R. K. Hermann, T. Risse, and M. B. Brewer, 129-157. New York: Rowman \& Littlefield.

Trenz, H.-J. 2015. "The Saga of Europeanisation. On the Narrative Construction of a European Society." In European Integration, Processes of Change and the National Experience, edited by S. Börner, and M. Eigmüller, 207-227. Palgrave Studies in European Political Sociology. London: Palgrave Macmillan. doi: 10.1057/9781137411259_10

Turunen, J. n.d. "Borderscapes of Europe - Cultural Production of (Colonial) Border Imaginaries through European Heritage." (Unpublished manuscript)

Wetherell, M., and J. Potter. 1992. Mapping the language of Racism: Discourse and the Legitimation of Exploitation. Hemel Hempstead: Harvester-Wheatsheaf. 